\title{
Time-related, cross-sectional and prospective follow-up of pancreatic endocrine function after pancreas allograft transplantation in Type 1 (insulin-dependent) diabetic patients
}

\author{
R. P. Robertson ${ }^{1}$, P. Diem ${ }^{3}$ and D. E. R. Sutherland ${ }^{2}$ \\ ${ }^{1}$ Diabetes Center and the Division of Endocrinology and Metabolism, Department of Medicine, ${ }^{2}$ Department of Surgery, University of \\ Minnesota Medical School, Minneapolis, USA and ${ }^{3}$ Diabetes Station, Bern-Inselspital, Bern, Switzerland
}

Summary. It has been established that successful pancreas transplantation in Type 1 (insulin-dependent) diabetic patients results in normal but exaggerated phasic glucose-induced insulin secretion, normal intravenous glucose disappearance rates, improved glucose recovery from insulin-induced hypoglycaemia, improved glucagon secretion during insulin-induced hypoglycaemia, but no alterations in pancreatic polypeptide responses to hypoglycaemia. However, previous reports have not segregated the data in terms of the length of time following successful transplantation and very little prospective data collected over time in individual patients has been published. This article reports that in general there are no significant differences in the level of improvement when comparing responses as early as three months post-operatively up to as long as two years post-operatively when examining the data crosssectionally in patients who have successfully maintained their allografts. Moreover, this remarkable constancy in pancreatic islet function is also seen in a smaller group of patients who have been examined prospectively at various intervals post-operatively. It is concluded that successful pancreas transplantation results in remarkable improvements in Alpha and Beta cell but not PP cell function that are maintained for at least one to two years.

Key words: Insulin - C-peptide - Glucagon Pancreas - Transplantation

\section{Introduction}

Transplantation of segments of pancreas from living related donors or whole pancreases from cadaveric donors, when successful, has been demonstrated to be the most effective way to maintain normal glucose homeostasis in Type 1 (insulin-dependent) diabetic patients (Sutherland et al. 1989). However, achievement of this degree of glucoregulation comes with the cost of the operative procedure, patient morbidity and patient mortality. Consequently, before accepting this operation as being effective over time in individual patients, it is essential to examine available data in a time-related, cross-sectional and prospective fashion in recipients with successfully functioning grafts. Using this analytical approach, this manuscript will report the results from intravenous glucose tolerance testing and insulin-induced hypoglycaemia testing to assess secretion of insulin, C-peptide, glucagon, pancreatic polypeptide, as well as intravenous glucose tolerance and glucose recovery from insulin-induced hypoglycaemia.

\section{Subjects and methods}

The general patient population as well as the methodology for intravenous glucose tolerance tests (Diem et al. 1990) and insulininduced hypoglycaemia tests (Diem et al. 1990) have been recently described. Briefly, all recipients were normoglycaemic and had normal haemoglobin AIC levels and none were receiving exogenous insulin or other medication for diabetes. Immunosuppression was achieved with the triple-drug regimen of azathioprine, cyclosporin and prednisone. The duration of diabetes mellitus in the recipients was $22 \pm 6$ years; the duration after pancreas transplantation was $14 \pm 15$ months with a range of three to 24 months. Radioimmunoassays for insulin, C-peptide and pancreatic polypeptide were as previously reported (Diem et al. 1990). Calculation for hormonal responses involved subtracting fasting basal levels of the hormone from the three maximal hormone levels following glucose stimulation in the case of insulin and C-peptide. Glucagon and pancreatic polypeptide responses are reported as maximal change over basal encountered during the test period. Glucose recovery is given as the maximal level of recovery expressed as percent of initial glucose level prior to insulin injection. $\mathrm{Kg}$ is calculated as the slope of the line reflecting the inverse correlation between time and the natural $\log$ rhythm of glucose concentration at 10, 15, 20,25, and $30 \mathrm{~min}$. after intravenous glucose injection $(20 \mathrm{gm})$. 


\section{Results}

The acute insulin responses $(\mu \mathrm{U} / \mathrm{ml})$ to intravenous glucose at 3,12 and 24 months were $119 \pm 20,133 \pm 31$, and $110 \pm 27$ for 15,25 , and 14 recipients when the data were analyzed cross-sectionally. None of these values differs significantly from one another (Fig. 1). A similar trend was observed when individual data from 10 patients who had been tested on at least two occasions post-operatively were examined (Fig. 1). Similar trends were observed when C-peptide (nmol/1) responses to intravenous glucose (Fig. 2) were observed. In this case, the values for the acute C-peptide response were $0.97 \pm 0.15,1.14 \pm 0.27$, and $1.40 \pm 5.3$ in 14,19 , and 8 patients when data were examined cross-sectionally.
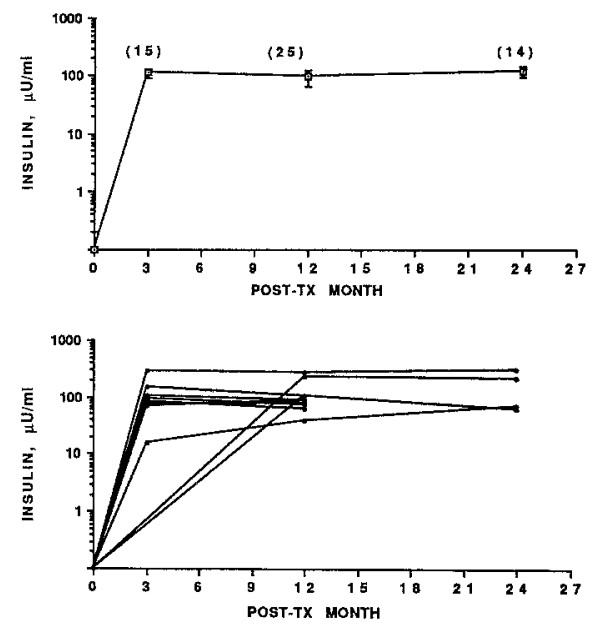

Fig. 1. Acute insulin responses to an intravenous injection of glucose $(20 \mathrm{~g})$ in recipients of pancreas allografts. Top panel illustrates cross-sectional data over 24 months. Bottom panel illustrates prospective data in ten subjects. TX=transplant.
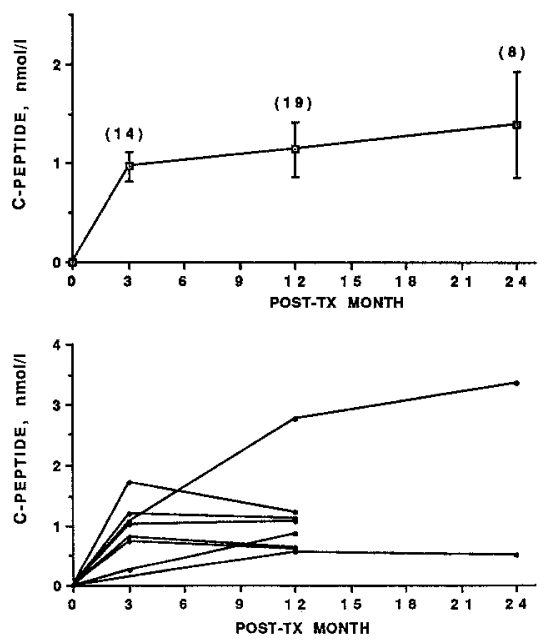

Fig. 2. Acute C-peptide responses to an intravenous injection of glucose $(20 \mathrm{~g})$ in recipients of pancreas allografts. Top panel illustrates cross-sectional data over 24 months. Bottom panel illustrates prospective data in eight subjects. TX=transplant.
Similar findings were observed in prospectively obtained data from eight patients undergoing testing on at least two separate occasions (Fig. 2).

Fasting plasma glucose levels $(\mathrm{mg} / \mathrm{dl})$ at 3,12 , and 24 months post-operatively were $88 \pm 11,86 \pm 11$, and $80 \pm 7$ in 15,24 , and 13 recipients (Fig. 3). None of these values were significantly different from one another. Stability in fasting glucose levels was observed when data from ten individual patients who had been studied serially on at least two separate occasions (Fig. 3). Similarly, there was a constancy in the glucose disappearance rates $(\% / \mathrm{min})$ at 3,12 , and 24 months with values of $1.49 \pm 0.16,1.53 \pm 0.12$, and $1.80 \pm 3.2$ in 14, 24, and 13 recipients (Fig. 3). Glucose disappearance rates also tended to remain stable in ten patients who were examined serially post-operatively (Fig. 3).
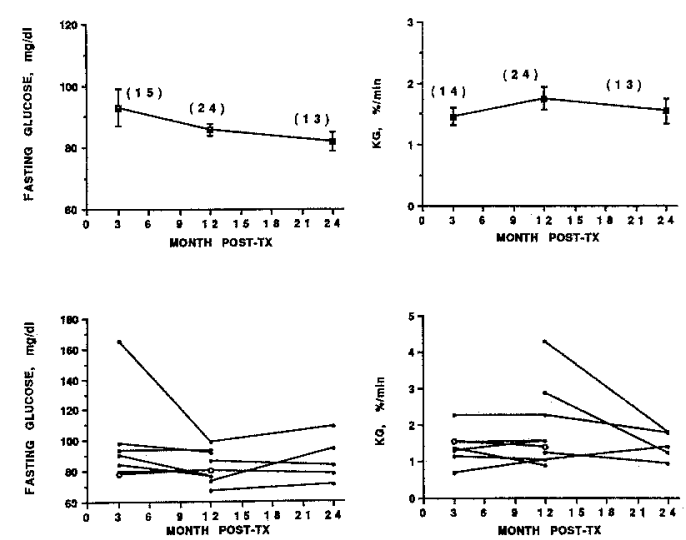

Fig. 3. Fasting glucose levels (left) and glucose disappearance rates (right) after intravenous glucose $(20 \mathrm{~g})$ injection in recipients of pancreas allografts. Top panel illustrates cross-sectional data. Bottom panel illustrates prospective data in ten subjects.

The ability of recipients to recover from insulininduced hypoglycaemia was improved as early as three months and they maintained this improvement up to 12 months when data were examined cross-sectionally. The percent recovery in glucose by $60 \mathrm{~min}$. following induction of hypoglycaemia pre-operatively, three months post-operatively and twelve months postoperatively was $40 \pm 2 \%, 64 \pm 3 \%$, and $61 \pm 2 \%$ in 35,10 , and 19 recipients when examined cross-sectionally (Fig. 4). A similar trend was observed when 15 patients were studied prospectively and serially on at least two separate occasions (Fig. 4). This improvement in glucose recovery from insulin-induced hypoglycaemia was associated with an improvement in glucagon secretion during hypoglycaemia. Cross-sectional data obtained pre-operatively, three months post-operatively and twelve months post-operatively revealed maximal glucagon $(\mathrm{pg} / \mathrm{ml})$ responses of $39 \pm 7,166 \pm 43$, and $228 \pm 46$ in 35,10 , and 18 recipients (Fig. 5). 
Improvement in glucagon responses was also observed in 14 patients who had been studied prospectively and serially during the post-operative periods (Fig. 5).
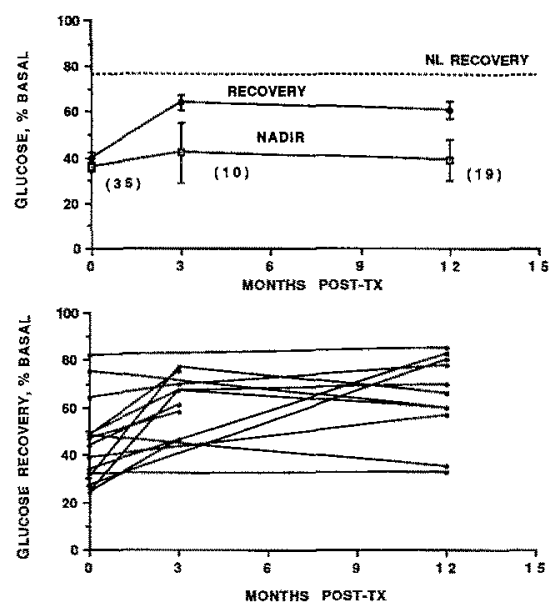

Fig. 4. Glucose nadirs and glucose recoveries after hypoglycaemia induced by intravenous insulin injection in recipients of pancreas allografts. Top panel illustrates crosssectional data over 12 months. Bottom panel illustrates glucose recovery data studied prospectively in 15 patients.
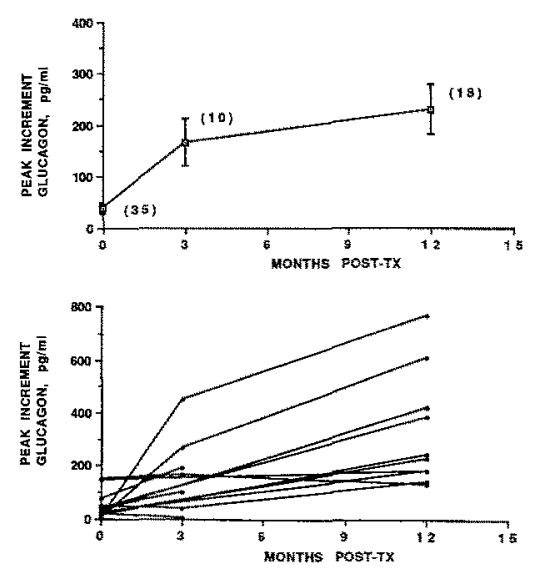

Fig. 5. Peak incremental glucagon responses during insulininduced hypoglycaemia in recipients of pancreas allografts. Top panel illustrates cross-sectional data. Bottom panel illustrates prospective data from 14 patients.

\section{Discussion}

We have previously published that successful pancreas transplantation in Type 1 diabetic recipients restores their ability to respond with biphasic insulin and $\mathrm{C}$ peptide responses during intravenous glucose tolerance testing (Diem et al. 1990). They also attain normal levels of fasting glucose, haemoglobin A1C and intravenous glucose disappearance rates. These results are consistent with earlier more brief reports (Land et al.
1987; Secchi et al. 1987; Ostman et al. 1989) and have been confirmed by a later lengthier report (Osei et al. 1990). We have also previously reported that successful recipients of pancreas transplantation improve their ability to recover from insulin-induced hypoglycaemia and that this is associated with improvements in glucagon responses to hypoglycaemia (Diem et al. 1990). In these reports we found no improvement in pancreatic polypeptide secretion. The only other earlier series reported post-transplant but no pre-transplant data for comparison (Bosi et al. 1988). The current manuscript combines our (Diem et al. 1990) older data with more current data to conduct a time-related, crosssectional and prospective analysis of endocrine pancreatic function post-operatively in recipients of successfully transplanted pancreas allografts. The results indicate a striking constancy in the improvement of insulin and Cpeptide responsivity to intravenous glucose as well as improvement in glucose disappearance rates. Similarly, the improvement in glucose recovery after insulininduced hypoglycaemia as well as glucagon responsivity to hypoglycaemia is remarkably constant. There is no indication that pancreatic polypeptide responses to insulin-induced hypoglycaemia improve.

It can thus be concluded that pancreas transplantation in Type I diabetic subjects, when successful, results in long-term improvements in pancreatic Alpha and Beta cell function and, consequently, improved glucose homeostasis without the need for exogenous insulin or other agents used to improve glucoregulation in the patients. However, it should be emphasized that there is as yet no concensus as to the medical indications for this procedure. It should be borne in mind that it involves a great deal of expense, patient morbidity and significant patient mortality.

Acknowledgements. We are indebted to the nursing and laboratory staff of the University of Minnesota General Clinical Research Center for skilled patient care and excellent technical assistance. In addition we thank Ms. P. Rossin for help with the preparation of this manuscript.

This work was supported by grants (R01-DK-39994 and M01RR-00400) from the National Institutes of Health and the Medical Research Service of the Department of Veteran Affairs. Dr. Diem was in part supported by a grant from the Swiss National Science Foundation.

\section{References}

Bosi E, Piatti PM, Secchi A, Monti LD, Traeger J, Dubernard JM, Pozza G (1988) Response of glucagon and insulin secretion to insulin-induced hypoglycemia in type I diabetic recipients after pancreatic transplantation. Diab Nutr Metab 1:21-27

Diem P, Abid M, Redmon JB, Sutherland DER, Robertson RP (1990) Systemic venous drainage of pancreas allografts as independent cause of hyperinsulinemia in type $I$ diabetic recipients. Diabetes 39:534-540

Diem P, Redmon JB, Abid M, Moran A, Sutherland DER, Halter JB, Robertson RP (1990) Glucagon, catecholamine and pancreatic 
polypeptide secretion in type I diabetic recipients of pancreas allografts. J Clin Invest 86:2008-2013

Land W, Landgraf R, Illner W-D, Abendroth D, Kampik A, Jensen U, Lenhart FP, Burg D, Hillebrand G, Castro LA, Landgraf-Lewis MMC, Frey L, Gokel M, Schleibner St, Nusser J, Ulbig M (1987) Clinical pancreatic transplantation using the prolamine duct occlusion technique: the Munich experience. Transplant Proc 19 (Suppl 4):75-83

Osei K, Henry ML, O'Dorisio TM, Tesi RJ, Sommer BG, Ferguson RM (1990) Physiological and pharmacological stimulation of pancreatic islet hormone secretion in type I diabetic pancreas allograft recipients. Diabetes 39:1235-1242

Östman J, Bolinder J, Gunnarsson R, Brattstrom C, Tyden G, Wahren J, Groth C-G (1989) Metabolic effects of pancreas transplantation: effects of pancreas transplantation on metabolic and hormonal profiles in IDDM patients. Diabetes 38 (Suppl 1):88-93

Secchi A, Pontiroli AE, Bosi E, Piatti PM, Touraine JL, Monti LD, Gelet A, Traeger J, Dubernard JM, Pozza G (1987) Effects of arginine and arginine plus somatostatin infusion on insulin release in diabetic patients submitted to pancreas allotransplantation. Diabete Metab 13:422-425

Sutherland DER, Dunn DL, Goetz FC, Kennedy W, Ramsay RC, Steffes MW, Mauer SM, Gruessner R, Moudry-Munns KC, Morel P, Viste A, Robertson RP, Najarian JS (1989) A 10-year experience with 290 pancreas transplants at a single institution. Ann Surg 210:274-288

Dr. R. P. Robertson

The Diabetes Center

Box 101 UMHC

University of Minnesota

Minneapolis, MN 55455

USA 